\title{
Marginally Adjusted Average LCA - Bridging the Gulf Between Attributional and Consequential LCA
}

\author{
Nigel Howard \\ Clarity Environment Consultancy, Beacon Hill, New South Wales, Australia
}

\section{Email address:}

Nigel.Howard@Clarityenv.com.au

\section{To cite this article:}

Nigel Howard. Marginally Adjusted Average LCA - Bridging the Gulf Between Attributional and Consequential LCA. Engineering Science. Vol. 6, No. 2, 2021, pp. 17-26. doi: 10.11648/j.es.20210602.11

Received: May 2, 2021; Accepted: May 17, 2021; Published: May 27, 2021

\begin{abstract}
Life Cycle Assessment (LCA) can often reveal unexpected or perverse outcomes from environmental initiatives. There are two main approaches to LCA: Attributional (ALCA) typically measures the impacts arising from producing a functional unit of product from average market suppliers and technologies. Consequential (CLCA) measures the marginal impacts to produce an additional functional unit of product, assuming that the resources consumed will come from new marginal supplies/technologies. As a result, ALCA and CLCA studies can give very different outcomes. The choice of method used for different LCA applications has divided practitioners and gives conflicting advice to decision-takers. The premise of this paper is that new production only causes marginal technologies to enter a market if the new producer specifically contracts the new marginal technology resources (e.g. Google sponsoring Solar Power for its operations). If the producer still purchases resources from average markets, then it is the aggregate demand in each market that motivates the entry of new marginal technologies and the effects of any addition should be shared with all co-consumers. The additional resources consumed are really the marginally adjusted average (MAA), not just the marginal. CLCA MAA results will usually closely resemble ALCA results, because entire markets are usually only perturbed to a small degree to meet new demand. In rare cases, where the existing market is substantially perturbed by an added demand, the CLCA results will differ significantly from the ALCA results. Many advantages are given for use of MAA to assess CLCA impacts, not least being to diminish the controversy between ALCA and CLCA outcomes.
\end{abstract}

Keywords: Consequential LCA, Attributional LCA, Marginal, Average, Marginally Adjusted Average, CLCA, ALCA, MAA

\section{Introduction}

Life Cycle Assessment (LCA) can often reveal unexpected or perverse outcomes from environmental initiatives and this is especially useful for examining the effectiveness of initiatives in industrial ecology. For example where the benefits from reuse or recycling of resources might be outweighed by added impacts from transport or reprocessing.

There are two main approaches to LCA: Attributional LCA (ALCA) and Consequential LCA (CLCA).

International standards $[1,2]$ do not differentiate ALCA from CLCA, but most authors acknowledge that Attributional LCA is defined by its focus on describing the environmentally relevant physical flows to and from a life cycle and its subsystems, whereas Consequential LCA is defined by its aim to describe how environmentally relevant flows will change in response to possible decisions [3]

The most authoritative definition appears to be within the
UNEP/SETAC 'Shonan Guidance Principles' [4]:

1) Attributional approach - System modelling approach in which inputs and outputs are attributed to the functional unit of a product system by linking and/or partitioning the unit processes of the system according to a normative rule.

2) Consequential approach - System modelling approach in which activities in a product system are linked so that activities are included in the product system to the extent that they are expected to change as a consequence of a change in demand for the functional unit.

Notwithstanding these definitions, many authors interpret both ALCA and CLCA in different ways. For the purpose of this this paper I will paraphrase these definitions more operationally as follows:

1) Attributional (ALCA) typically measures the impacts arising from producing a functional unit of product from average market supplies and technologies. 
2) Consequential (CLCA) typically measures the marginal impacts to produce an additional functional unit of product, assuming that the additional resources consumed will come from new marginal supplies and technologies. (CLCA might also address the consequences of removing a functional unit of product)

ALCA and CLCA often produce very different results and it has been a matter of contention for many years as to which approach should be used to answer different questions and which best represents the environmental performance of products/services (products hereon refers to products or services) and which should be used for different types of LCA studies (e.g of products, services, planning and policy informing, Environmental Product Declarations (EPDs) and Ecolabels).

This paper questions the way consequence is modelled in CLCA and proposes that consequence really acts through marginal changes perturbing the average markets for resources and not directly targeted to a specific product unless this is specifically contracted. CLCA should therefore model consequence acting through the marginally adjusted average.

\section{Literature Review}

The different perspectives are thoroughly reviewed by Finnveden et al [5], especially in section 3 which specifically addresses attributional and consequential LCA.

A key factor in deciding whether to use ALCA or CLCA is the type of question to be answered through the Goal and Scope definition [6]. Guine' et al distinguish three main types of questions, occasional one-off choices, structural choices regularly supplied and strategic choices [7]. Scope is also important - how to supply a function for a shorter or longer time periods may require ALCA or CLCA modelling and different types of data, since they have different scales in terms of reach, timescale and consequences. If the LCA is simply gauging current environmental performance as a product attribute, then ALCA may be preferred, but if the LCA is informing a specific decision, especially one with longer term broader ranging consequences then CLCA may be preferred. Choosing CLCA implies greater uncertainties so the insights gained must outweigh these uncertainties. For this reason, ALCA tends to be more broadly applied [8]. Weidema [9] argues that consequential LCA is more relevant for increasing the understanding of the product chain and identifying the most significant improvements. Many authors argue that both ALCA and CLCA can legitimately be used for most types of decisions (e.g., Ekvall [10]; Sande'n and Karlstro“m, [11]). However, when ALCA and CLCA so often give conflicting results, this is not a sound basis for providing practical actionable advice to decision-takers.

There is a rich literature discussing how scenarios of consequence are modelled and to how many layers of consequence:

Tillman [12] discusses the key methodological choices in LCA in the modelling of subsystems of the life cycle. ALCA uses data representing the average environmental burdens for producing a unit of product. CLCA uses marginal data representing the effects of a small change in the output of goods and/or services. Average or marginal data are normally considered to be non-commensurable alternatives to be used to model consequence - ALCA excludes the use of marginal data and CLCA uses marginal data when relevant for assessing consequences, but uses average data where this still best represents marginal additions [13]. Timeframe is also important because short-term effects change the utilisation of the existing production capacity from existing technologies, but long-term effects can involve changes in the production technologies.

Weidema et al [14] present a five step procedure to identify the long-term marginal technology. Other authors argue that the most complete description of the consequences is obtained if both short and long-term effects are accounted for (Eriksson et al [15]).

Finneveden et al [5] recognise the potential complexity and large uncertainties in the scenarios involved in identifying the marginal effects and how complexity and uncertainty grow over time.

Consequences can be multi-layered and this compounds the uncertainties:

1) There can be positive and negative feedback and rebound effects and supply/demand perturbations, with extensive discussion of the use of equilibrium and partial equilibrium analysis to quantify the consequential scenario effects (Weidema [9], Ekvall and Weidema [13], Lundie et al [8], Ekvall [16], Ekvall and Andrae [17] and Lesage et al. [18, 19], Kløverpris et al [20] Ibenholt [21], Finnveden et al [5].

2) More efficient or cost effective technologies can provide savings that may be spent elsewhere with knock-on consequences. Thiesen et al [22] used statistical data to estimate the likely alternative expenditures for Danish consumers.

3) There can be savings in time or space that alternative activities will fill (Spielmann et al [23]; Weidema et al [24])

4) There can be knock-on effects on the technologies, economies and efficiencies from scale and experience. (Claeson [25], Ekvall et al [26], Sande'n and Karlstro“m [11], Mattsson [27]).

5) There will be transitions over time from non-renewable resources to alternatives Stewart and Weidema [28]. This is also considered in impact assessment by Steen [29] and by Goedkoop and Spriensma [30].

6) The choice between attributional and consequential LCA will also influence system boundaries, the use of substitution or allocation and the definition of functional unit (Rebitzer et al [31]) and the choice to include or exclude or specify particular life Cycle Impact Assessment (LCIA) methods.

CLCA is therefore inherently more complex than the static model of an ALCA and less certain, because it requires scenarios to forecast into the future and must include economic modelling to reflect elasticity and effects on supply and demand. CLCA results can be very sensitive to assumptions, methodological choices, timeframe and layers of consequence included (Mattsson et al. [32]). 
Although there is a rich literature on which consequences should be included in the CLCA scenarios, it is generally assumed that ALCA impacts are calculated from the average data supply chains and CLCA impacts are calculated from marginal data supply chains except where the most appropriate marginal data is considered to be the same as the average data.

However, when a new product is introduced to a market, causing the marginal addition of demand from the suppliers supply chains, there is no mechanism by which marginally added resources to meet this demand are specifically and uniquely supplied to the new product. What really happens is that the average supply that all co-consumers procure from, becomes marginally adjusted by every new product added (or old product displaced/removed).

This paper proposes an alternative interpretation of causality in CLCA based on the marginally adjusted average (MAA) supplies that all co-consumers share. The author believes that this better models reality than assigning each marginal change uniquely to each new product added and might help to reconcile Attributional and Consequential LCA.

\section{Method}

The method adopted for this study comprised literature survey, critique and objective argument, illustrating key points with fictitious simplified examples to propose an alternative approach to conducting Consequential LCA which reconciles with methodology for Attributional LCA.

\section{Discussion}

\subsection{Attributional LCA}

This traditional approach to LCA describes the environmentally relevant physical flows to and from a life cycle and its subsystems (Curran et al [3]). ALCA attempts to measure the current environmental performance of a product based on current (or strictly speaking recent past) data.

The method described in the ISO standards [2], commences with defining a goal and compatible scope and functional unit for the product being studied. The scope leads to the definition of physical and temporal boundaries/timeframes. The boundary defines the point at which flows of resources are measured as inputs or outputs to the process (es). What goes in must come out, so following thermodynamic principles we must have a closed boundary and mass/elemental/thermodynamic balance between the measured input and output flows.

ALCA attempts to measure the current (as-is) environmental performance of a product/service as an attribute, without attempting to predict for the future. Often though there is an implicit assumption that future performance will be similar to current performance and sometimes the LCA spans a timescale where this may not be a reliable implicit assumption. In these cases perhaps a consequential study is better justified. ALCA studies can be scoped at many different levels to provide focussed guidance for different purposes and decision-takers without excessive distraction by remote consequences beyond the influence of the immediate product or its producers. Yang $[33,34]$ argues that all LCA is essentially consequential. (somewhat ignoring the use of LCA to simply gauge environmental performance for market competitive reasons (Ecolabels) or to provide data for Environmental Product Declarations (EPD's). From a perspective where all LCA is considered consequential, ALCA is considered to be a linear model of average data for CLCA.

An inventory of input and output flows of resources, products and co-products, wastes and material for recycling is compiled. In ALCA the data used is as-far-as-possible specific to the product/service, but the impacts from upstream resources or downstream wastes will typically be the most relevant average data (Tillman [12]). The flows are measured in absolute (average market) terms. For example, if the production of a product consumes $1 \mathrm{MWh}$ of electricity from the Australian grid, then the inventory would include the impacts from $1 \mathrm{MWh}$ of grid connected electricity - typically predominantly black coal, brown coal and gas fired. If the producer had specifically contracted with a renewable energy supplier, then the inventory would include the impacts from $1 \mathrm{MWh}$ of renewable electricity modelled as part of the foreground system. For example, in Australia, Bluescope Steel are specifically contracting $1 \mathrm{GW}$ of solar electricity to run the Port Kembla steelworks. By contrast, Whyalla steelworks operated by OneSteel adds demand for electricity to the grid in Southern Australia with no specific contracts for renewable electricity. Where several co-products arise from the same process, the inventory of inputs and outputs will usually be allocated between the co-products but it is sometimes possible to use system expansion to eliminate a co-product (provided the system boundary is not breached by the expansion). There is much controversy over how this should be done (Weidema and Schmidt [34]), but economic allocation is the only method that can be used with universal consistency. In addition, there is a cause/effect relationship between the money invested in establishing and operating the process (cause) and the return on investment from the flow of economic returns from sale of the co-products (effects) and the process will be optimised for these economic returns). For these reasons economic allocation is preferred by the author.

Having compiled the allocated inventories of flows, these can be classified, characterised, normalised and weighted using a number of different impact assessment models.

The resulting environmental impact results can then be used for a wide range of purposes - to identify environmental issues, to improve processes, to improve procurement, to develop promotional material, to make an Environmental Product Declaration (EPD) to submit for an Ecolabel, to judge a product as worthy of an Ecolabel, to provide data to others for a broader scope LCA, to facilitate planning or policymaking decisions.

\subsection{Consequential LCA}

CLCA has a different philosophical approach. CLCA aims to describe how environmentally relevant flows will change 
in response to possible decisions (Curran et al [4]). As such, CLCA attempts to forecast the future consequences of adding a new product or service. The assumption in CLCA is that any product added to the existing market will have the consequence of adding just the marginal additions of input or output flows that are affected and only these should therefore be considered as accounting for the product's consequential environmental performance. (In some cases and where justified, the marginal addition will be the same as the market average per unit of production).

Where the market dynamics are known then CLCA adopts the marginal market consequence of adding a product. According to Consequential-LCA [36], "If the market is generally increasing (or decreasing at a rate less than the average replacement rate for the capital equipment), new capacity must be installed, typically involving a modern, competitive technology". Consequential-LCA [36] also states "As a default, when information on market trends is not available, an increasing market may be assumed, since this is - in spite of obvious exceptions - the general situation for most products, due to the general increase in population and wealth." Hence, any new product added will tend to always benefit from the newest, most efficient/cost-effective new technology, whilst existing producers will apparently carry the average market performance even though the producer may in practice procure exactly the same resources from the same markets as the pre-existing producer. This means that if a new product consumes $1 \mathrm{MWh}$ of electricity per tonne of production then the added $1 \mathrm{MWh}$ of electricity demand will be presumed to be met by the most likely added technology needed to meet the additional electricity demand - in Australia this demand would be instantaneously met by gas fired dispatchable generation, but over the longer term this demand would most likely be met by increases in renewable (wind or solar powered) electricity even if the producer is actually consuming electricity from the grid exactly the same as the pre-existing producer. It is normal convention to use the long-term marginal supply technology in CLCA. (Consequential-LCA [36])

Within CLCA datasets, CLCA is presumed to apply to all products/services as though they are new additions to an existing market. Paradoxically this means that (except where the average market is chosen to best represent the marginal change) no product assessed using CLCA appears to actually be burdened with the real current average market mix of technologies that ALCA assumes, even though all producers will predominantly procure their resources from the average markets. This is a significant reason for the different results for individual products predicted by CLCA compared to ALCA.

As a matter of principle, CLCA attempts to predict future consequences and this implicitly (if not explicitly) relies on scenarios for forecasting the future. (Some might argue that where the scenario is just an extrapolation of the past into the future using average technologies, this does not constitute a scenario, but to the author this is still an implicit scenario.) Reliance on scenarios is a major strength of CLCA for longtimescale or broad reach projects - e.g. informing policymaking or planning. This is a second but appropriate reason for the different outcomes predicted by CLCA compared to ALCA. This may also be a vulnerability since the scenario chosen can significantly determine the outcomes predicted (Mattsson et al [32]) and might be subject to practitioner or sponsor bias.
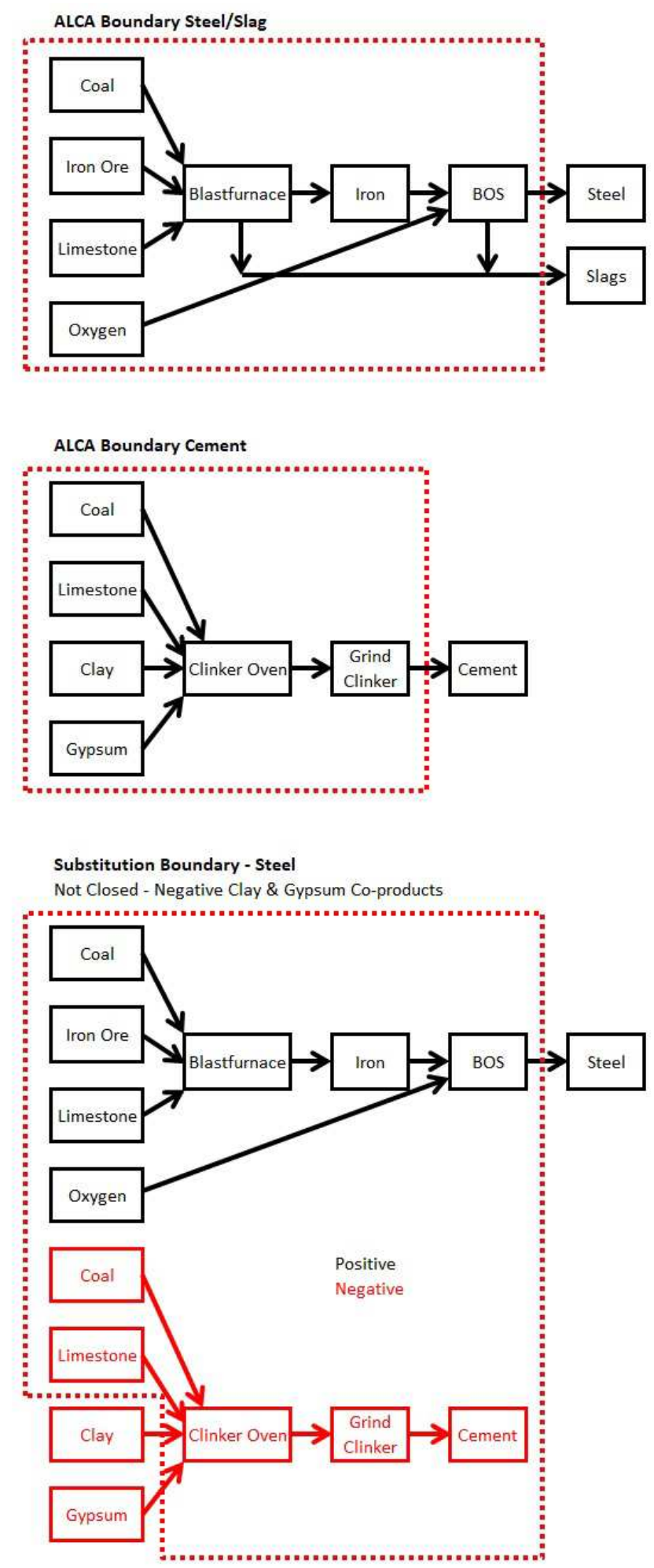

Figure 1. Indicative Process Block Diagram and Boundaries - ALCA Steel and Cement, CLCA Steel. 
The final major difference in CLCA is that the contentious step (in ALCA) of allocation is often avoided by substituting away co-products to leave a single product inventory (Weidema and Schmidt [35]). So for example during electricity generation, fly-ash is coproduced that is then used as a substituent for cement clinker in cement production. To isolate the electricity as a unique product, the co-produced fly-ash is subtracted from the output inventory and an equivalent quantity of the cement production process is subtracted from the input inventory.

An important distinction now arises with ALCA - the boundary for the CLCA study must now wrap around the cement production process, but the production of cement also consumes clay and gypsum that were not part of the electricity input inventory, so either the inventory must now contain negative quantities of clay and gypsum (paid back outside the boundary the boundary has really been breached) or additions of clay and gypsum must be made to balance the inventory to cancel out these new negative co-products and the boundary must now also wrap around clay and gypsum extraction and transport (Figure 1). This aspect of CLCA methodology has a huge tail of consequences almost all inventories will contain transport which derives its fuels from oil refining which has a multitude of co-products which are ubiquitous in all modern economies. Once the long tail of substitutions for all resources has been encompassed, from an ALCA perspective, the study has come close to being globally bounded. This is not a problem in CLCA because a global boundary is usually considered integral to the method and is justified as essential to span the full life-cycle (Wiedema [37]).

Lastly, recycling extends these consequences temporally. Recycled materials are also modelled by substitution, but now there is a time delay through the use phase between the production and recycling activity. For infrastructure, this time delay can be centuries. (That is why we see a huge discrepancy between the known $95-99 \%$ recycling rates for steel but only $10-30 \%$ of post-consumer steel returning to be used as recycled content in new steel. Steel is extensively used to build developing world infrastructure with life-spans of 100300years. The growing stock of steel in worldwide infrastructure allows steel production capacities to go up 3-10fold over the $300 y$ ear use period, reducing the $95 \%+$ recycling rate to just $10-30 \%$ of the production $100-300$ years into the future). To preserve mass / elemental / themodynamic balance CLCA studies must be globally bounded physically and temporally unbounded. This is both a problem and an advantage. CLCA truly spans the full range of marginal consequences, whilst ALCA measures only the impacts focussed on the defined physically and temporally bounded scope. Some results for future long-term recycling appear to use a CLCA approach to give recycling credit against attributional LCA results implying that they are an immediate benefit. These results are highly misleading of the true benefits of recycling and compromise inter-generational equity. Regrettably, this is the approach that is incorrectly mandated by CENTC350 WG3 to be used in assessing recycling benefits for EN15804 [38] compliant Module D EPD reporting.

Impact assessment methods and models are similar for both ALCA and CLCA.

\subsection{A Critique of Attributional LCA}

From a CLCA practitioners perspective, ALCA results may appear misleading of the true impacts from products and services studied because:

1) the addition of a new product/service only results in the additional consumption of the marginally added resources to produce the new product/service (For example adding electricity demand from renewables in Australia). As such for the new product added, ALCA is determining the performance of market average technology that is not actually being added as a result of the added production. For the added production, the average market performance should be considered irrelevant - the new product has only added consumption of the newest technology resources.

2) the physical and temporal boundaries of ALCA constrain the scope of the performance assessment, calling into question whether the study qualifies as a full "Life Cycle Assessment".(Wiedema 2016)

\subsection{A Critique of Consequential LCA}

From an ALCA practitioners perspective, CLCA results may appear misleading of the true impacts from products and services studied because:

1) scenarios are adopted that assume the marginal resources consumed come from the latest, most efficient technologies (e.g. renewable electricity in Australia), even when in reality (unless specifically contracting these resources e.g. Google contracting for Solar Energy to meet its full electricity needs [39]), the producer is consuming the marginally adjusted mix of average market technologies (In Australia and most other countries coal fired electricity generation still predominates).

2) within CLCA databases, all products and services are treated as new additions and generally modelled as consuming the latest technology marginal resources, regardless of the actual supply chain technologies that producers really procure their resources from. As a result no products/services appear to be held accountable for the average market technologies that in reality they all are consuming.

3) since, the CLCA results do not account the true impacts from the average technologies actually consumed these results do not signal the opportunity or benefits from a producer minimising their impact in these average technologies, indeed they signal complacency to these opportunities. (e.g. their impact profile already assumes renewable electricity as the marginal supply so installing renewable electricity generation on-site to reduce their actual, predominantly coal fired grid impacts gives no apparent improvement to their impact profile).

4) normally, if a product/service is removed from production, it is assumed that the same best technology resources are removed as when the product/service is 
added. In Australia, the immediate marginal source of electricity is dispatchable gas fired electricity, because it can respond in minutes to demand changes, the longterm trend in added supply is from renewables and this is the normal CLCA assumption. However the longterm marginal trend for reducing loads is the retirement of brown/black coal fired generation. Provided the longterm trend is for the net demand to always be increasing, then always using renewables as the marginal technology is considered appropriate, but if a substantial load is retired - say an Aluminium smelter, then likely the opportunity to retire coal fired capacity would be taken. If the CLCA methodology does not explicitly consider this, then using renewables as the marginal technology would give misleading results. In general, by considering only the marginal effects as directly and uniquely attributable to the added product, CLCA results will be blind to changes that may be happening in the average markets that producers really consume from - e.g. the transition from fossil powered to renewable energy in Australia.

5) CLCA results can pass through large step changes as one marginal resource scenario transitions to another whilst the average market resources that are really being consumed make only slow transitions.

6) CLCA results may include a long tail of consequences remote from the power-to-act of immediate decisiontakers because they are globally bounded physically and unbounded over time. As such the results may be academically more complete, but may be practically of limited benefit for informing more focussed decisions.

An extensive literature review and commentary with recommendations for standardising aspects of CLCA methodology has been provided by Zamagni et al [40].

\subsection{Consequential Marginally Adjusted Average LCA (MAA LCA)}

The author believes that the current practice of attributing the marginal consequences from adding a new product uniquely to that new product does not reflect reality very well and proposes a new way of looking at consequence in LCA that bridges the gulf between ALCA and CLCA.

In reality, the marginal effects of adding a new product are to marginally adjust all of the markets that supply products/resources or consume wastes from the new product. As such the addition of a new product marginally adjusts the average impacts from all of the markets affected and then procures and consumes its share of those products/resources. The MAA in the affected markets is calculated as follows:

$$
M A A=A v \times\left(1-\frac{P \%}{100}\right)+M a \times\left(\frac{P \%}{100}\right)
$$

Where:

$M A A=$ Marginally Adjusted Average impact $A v=$ Prior market Average impact

Ma $=$ Added Marginal impact due to the added demand
$P \%=$ Percentage addition to the pre-existing market due the added demand

Please note that the MAA changes do not occur in the added processes themselves, but occur in all of the markets that supply additional resources/products to meet the added demand and then flow as consequences into the added product that caused the market perturbations.

The marginally adjusted average impacts due to the new product are shared with all co-consumers of the resources consumed to the extent that they share the market $(\mathrm{P} \%)$ for each resource. This approach to modelling appears to more truly reflect the consequences of any new addition and its consequential additional resources consumed.

\subsection{Benefits of $M A A C L C A$}

The benefits of adopting this approach to modelling consequence in CLCA appear to be numerous and significant:

1) The impacts from the additional resources consumed and wastes generated are only marginally adjusted from the pre-existing average market impacts for all resources. As a result, the ALCA results and the "Marginally Adjusted Average" CLCA results will usually be very similar. In fact they will only differ significantly where the marginal addition of a product/service is materially disruptive of its supply chains from prior average markets - exactly where a CLCA would be of most value compared to an ALCA.

2) The marginal adjustment is shared with all co-consumers in all of the affected markets. Without losing the distinction between an attributional and consequential study, the impacts of resources from the average technology market are now fully accounted for appropriately and shared between all co-consumers of these resources. There is no misleading impression that all products/processes are only consuming resources from the latest technology, lowest impact supply chains. In cases where average data is already used as identical to the marginal, the MAA would also be unchanged from the average.

3) There is a progressive transition in CLCA results as marginal changes cause the marginally adjusted average (MAA) to transition with the changing mix of technologies and their impacts, with no step changes as a new technology becomes the dominant new marginal.

4) The MAA CLCA results reveal where a producer can still have significant impact on the procurement and consumption of average technology resources and where a deliberate choice to procure the newest, low impact technology (say renewable energy) can benefit the producer and product profile. The market average technologies, which in reality dominate all production are not left unaccounted within CLCA datasets.

5) Where a process is phased out of production for whatever reason, the MAA will appropriately accommodate this reduction in demand and production just as well as an added new product increases demand and consumption of resources, with no step changes. This is especially important for markets in major transition like electricity 
generation transitioning from fossil powered to renewables powered. In CLCA the implied assumption is that this transition has already happened.

6) Only the producer that specifically contracts a new, lower environmental impact technology (e.g. renewable electricity) would be able to claim $100 \%$ of the new technology applying to their processes/products. If this unique contract for the low impact technology is cancelled then the producer reverts to the average market that they buy from and the renewable resource would no longer be generated or consumed.

7) The biggest difference now between an ALCA and a CLCA based on marginally adjusted averages will appropriately be due to the consequential objective and the global and timeless scope of the CLCA compared to the bounded scope of the ALCA. This would make the immediate results from ALCA naturally transition into the long-term unbounded, scenario based forecasting results for the marginally adjusted CLCA, ideally used for say planning and policymaking type decisions. ALCA and CLCA become allied but distinguished by attributional or consequential objectives.

8) Finally, CLCA methodology typically ignores that most new products entering an existing market do not really create new demand, their effect is primarily to take market share from prior existing suppliers. Strictly following CLCA logic, only the new demand should be regarded as additional and that taking market share from other producers should be ignored as non-additional. Since we usually want to assess the impacts for the full production capacity of a process, then even following CLCA logic, the majority of production should be assigned the average resource flows (pre-existing) whilst that genuinely added new demand might be assigned the marginal only resources. Using the MAA for the full production capacity appears to better model this situation.

Figure 2 diagrammatically illustrates how the different viewpoints work for a fictitious product consuming 100 units of resources with an average technology impact of 10 pollution units (Figure 2a). If this market is perturbed by the addition of 2 units of resources with an impact of 5 pollution units and the displacement/removal of 1 unit of resources with an impact of 15 pollution units, Figure $2 \mathrm{~b}$ shows the ALCA viewpoint resulting in 0.098 pollution units per product unit. Figure 2c shows the current typical CLCA viewpoint, whereby it is assumed that demand is always increasing such that only the marginal addition of resources need be considered, resulting in an impact of 2.5 pollution units of impact per product unit. (This does not preclude the recognition of displaced demand where this is explicitly recognised, but it is not the default assumption). The MAA CLCA viewpoint (Figure 2d) produces similar (0.098 pollution impacts per unit of product) results to the ALCA, because the result is dominated by the average markets that the resources are procured from and the marginal change is a marginal change to this average market and not uniquely attributed to the new product added (or removed).

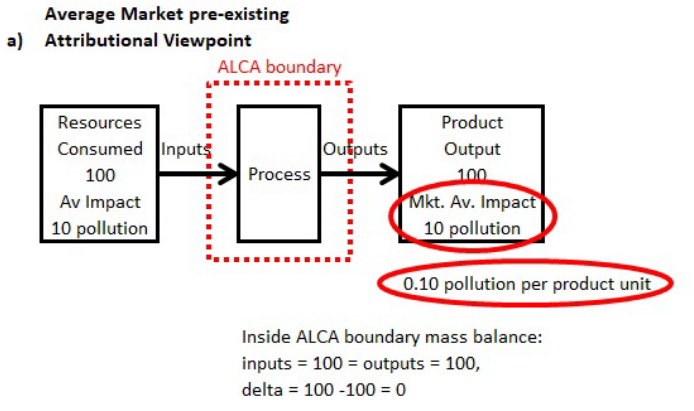

Add 2 units of demand of marginal impact 5 , Remove 1 unit of demand of marginal impact 15

b) Attributional Viewpoint

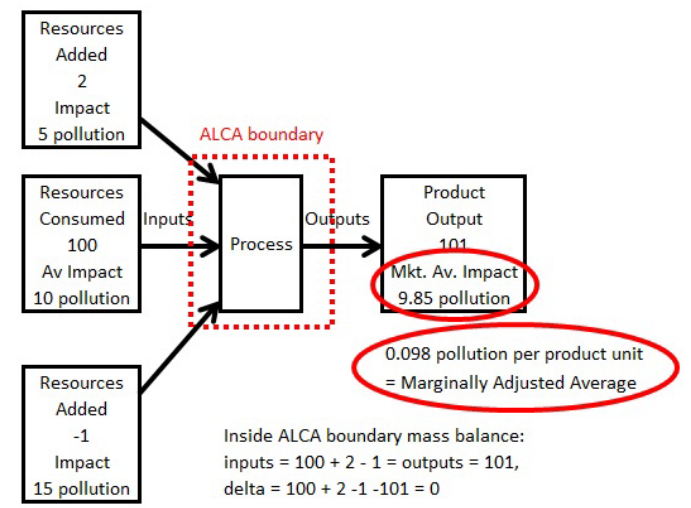

c) Consequential Viewpoint

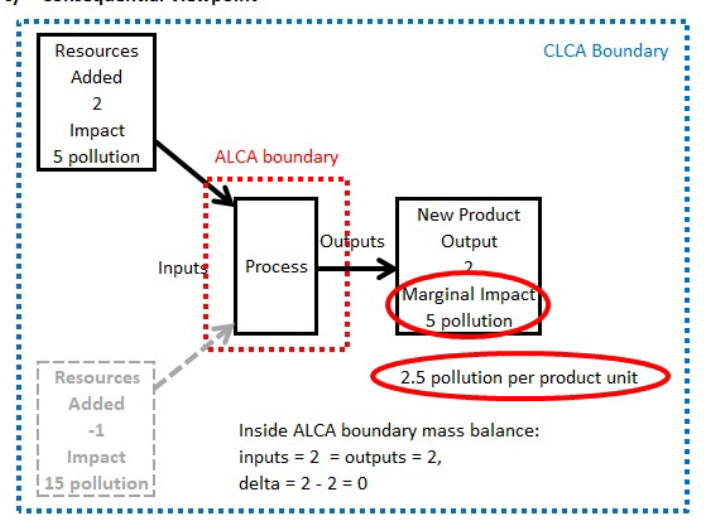

d) Marginally Adjusted Average Consequential Viewpoint

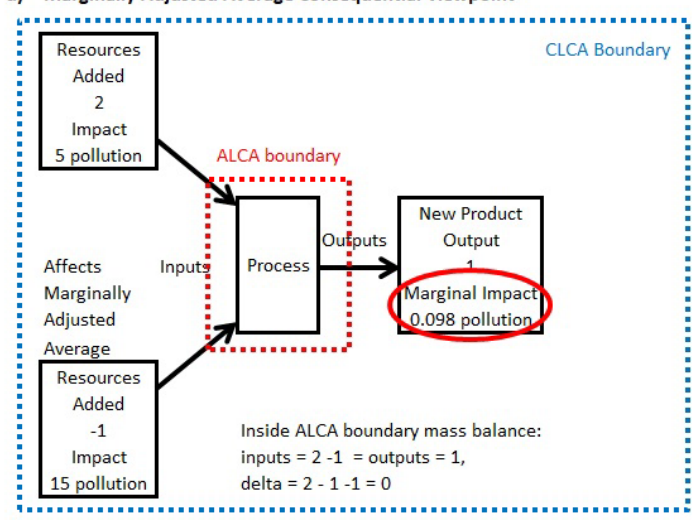

Figure 2. Diagrammatic Representation of ALCA, CLCA and MAA CLCA for Market Perturbed by Addition and Removal of Resources.

Please note that use of the MAA does not change the CLCA into an ALCA because we are still assessing the 
impact of adding a functional unit of product, we are just saying that the added resources consumed comes from the marginally adjusted market not uniquely from the marginally added technologies/supplies.

INPUTS

OUTPUTS

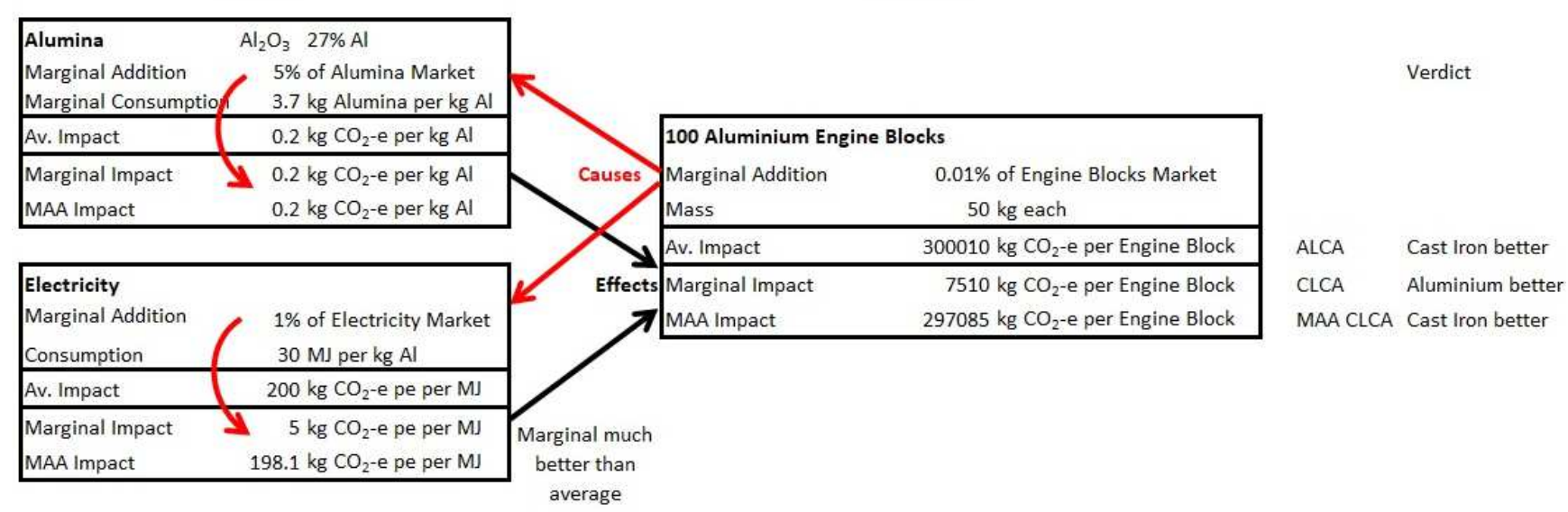

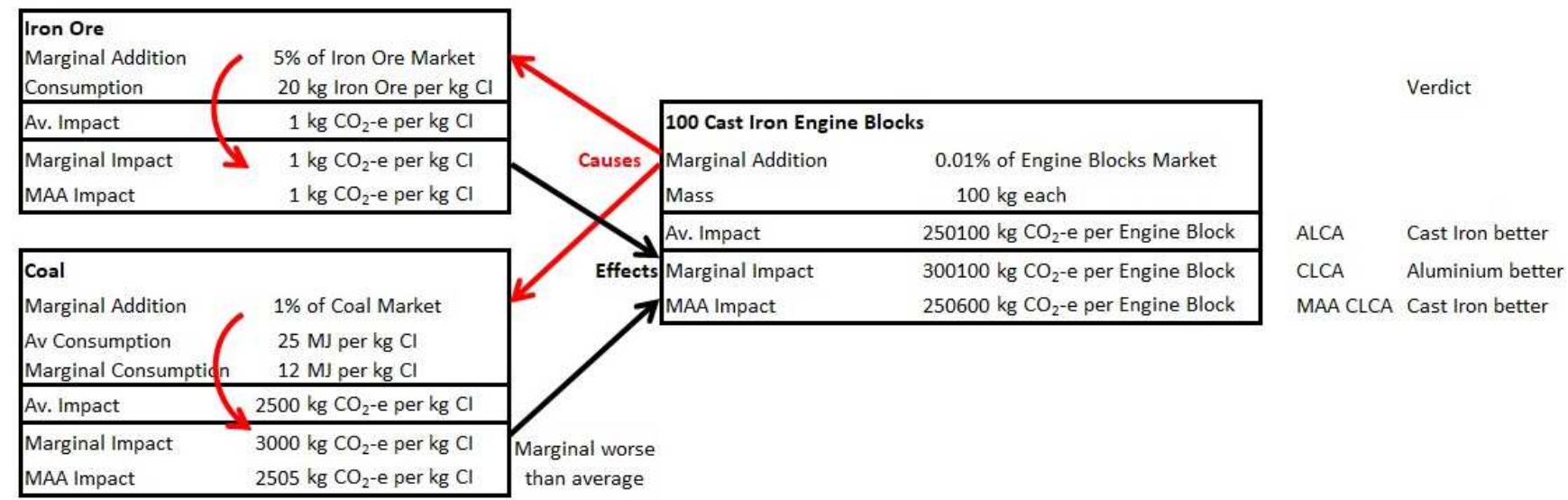

Figure 3. Fictitious Comparative Example of ALCA, CLCA and MAA CLCA for Aluminium or Cast Iron Engine Blocks.

In this illustrative example the marginal difference for the Aluminium is assumed to come only from the electricity input, with the Alumina marginal impact being the same as the average. Practically this might be due to renewable electricity assumed as the marginal source rather than predominantly coal fired grid electricity as the average source. The marginal difference for the Cast Iron is assumed to come only from the coal used, with the Iron Ore marginal impact being the same as the average. Practically this might be due to lower grade coal now available to new producers perhaps.

The results for adding 100 Aluminium and Cast Iron engine blocks are shown in the outputs column. The results show the ALCA average impacts, the CLCA marginal (exclusively applied to the product) impacts and the MAA CLCA marginal (shared between all co-consumer) impacts. Note that to determine the MAA, we now additionally need to know the proportion of the market that each marginal addition represents for each resource supplied. This additional information is commonly documented in LCA studies.

The results show that if the consequence of a marginal addition is to perturb all of the upstream markets that all consume from (as represented by the MAA CLCA), then the preferred product is the Cast Iron engine block, even though the Aluminium engine block provides a lower marginal impact addition. This occurs because although in practice, the Aluminium engine block producer will still procure electricity from the average grid, the CLCA marginal addition of renewable electricity assumes this intrinsically simply because the Aluminium product consumes electricity. The MAA CLCA result still signals to the producer that a specific investment in renewable electricity will benefit the product's profile substituting the MAA with a specific low impact renewable electricity profile, whereas the CLCA marginal only result makes the producer complacent to this opportunity.

\subsection{Boundaries and Averages in Consequential Marginally Adjusted Average (MAA) LCA}

"Hybrid LCA" can be problematic for mixing bounded scope ALCA data with globally bounded I/O scope data such that the results are neither meaningful from a bounded scope perspective or from a globally bounded scope perspective. Unsurprisingly, the globally bounded I/O scope data appear to have exaggerated importance compared to the much more tightly bounded ALCA scope data. It is very important 
therefore that CLCA using the MAA:

1) Either adopts bounded scope ALCA average data together with consistent allocation to co-products rather than substitution to eliminate co-products.

2) Or adopts only global scope average data with substitution throughout, aligned with the traditional CLCA approach and principles.

Bounded scope ALCA average data should only ever be used with substitution where the boundary can be expanded to fully contain the substituting products - this should ensure that negative flows or impacts cannot arise.

For globally bounded and temporally unbounded scope CLCA data, apparent negative flows inside any sub-boundary are compensated outside of the sub-boundary but within global bounds or into the future (temporally unbounded).

\section{Conclusions}

The author believes that MAA CLCA results better match reality and are less misleading because:

1) The environmental impact results relate specifically to the marginally adjusted average resources actually procured to produce the products. Equally, they respond appropriately to specific procurement decisions (e.g. to purchase renewable electricity).

2) Average consumption is still attributed to and shared by all producers in addition to the way their products perturb the average, whereas the attribution of the marginal only components to each product as though it were an addition makes no products responsible for carrying the average market impacts that in practice all procure and consume from.

3) Transitions in impact assessment due to successive marginal perturbations of the average markets appear to better reflect reality than the step-wise transitions that may occur when a new marginal technology arises or an old technology is retired.

4) The implicit assumption that all marginal consequences are additional is resolved by the MAA, which can respond to both marginal additions and removals (and can even cope with simultaneous additions and removals - e.g. displacement of an old technology with a new one).

5) That MAA CLCA may create a bridge to harmonising CLCA with ALCA.

\section{Recommendations}

That CLCA using marginally adjusted average data be further explored and critiqued and if not found wanting, be widely adopted within LCA practice.

\section{References}

[1] ISO 2006a. ISO 14040 International Standard. In: Environmental Management - Life Cycle Assessment Principles and Framework. International Organisation for Standardization, Geneva, Switzerland.
[2] ISO. 2006b. ISO 14044 International Standard. In: Environmental Management - Life Cycle Assessment Requirements and Guidelines. International Organisation for Standardisation, Geneva, Switzerland.

[3] Curran M A, Mann M, Norris G. 2005. The international workshop on electricity data for life cycle inventories. J. Cleaner Prod. 13 (8), 853-862

[4] UNEP. 2011. www.unep.org/pdf/Global-Guidance-Principlesfor-LCA.pdf.

[5] Finnveden G, Hauschild M, Ekvall T, Guinée J, Heijungs R, Hellweg S, Koehler A, Pennington D, Suh S. 2009. Recent developments in Life Cycle Assessment. Journal of environmental management 91 1-21101016/jjenvman2009618.

[6] Consoli F, Allen D, Boustead I, Fava J, Franklin W, Jensen A A, de Oude N, Parrish R, Perriman R, Postlethwaite D, Quay B, Sie'guin J, Vigon B (Eds.). 1993. Guidelines for Life Cycle Assessment. A Code of Practice. SETAC Press, Pensacola, FL.

[7] Guine'e J B, Gorre'e M, Heijungs R, Huppes G, Kleijn R, de Koning A, van Oers L, Wegener Sleeswijk A, Suh S, Udo de Haes H A, de Bruijn J A, van Duin R, Huijbregts M A J. 2002. Handbook on Life Cycle Assessment: Operational Guide to the ISO Standards. Series: Eco-efficiency in Industry and Science. Kluwer Academic Publishers, Dordrecht.

[8] Lundie S, Ciroth A, Huppes G. 2007. Inventory methods in LCA: towards consistency and improvement - Final Report. UNEP-SETAC Life Cycle Initiative.

[9] Weidema B P. 2003. Market Information in Life Cycle Assessment. In: Environmental Project No. 863. Danish Environmental Protection Agency, Copenhagen.

[10] Ekvall T, Tillman A M, Molander S. 2005. Normative ethics and methodology for life cycle assessment. J. Cleaner Prod 13 (13-14), 1225-1234.

[11] Sande'n B and Karlstro"m M. 2007. Positive and negative feedback in consequential life-cycle assessment. J. Clean. Prod. 15, 1469-1481.

[12] Tillman A M. 2000. Significance of decision-making for LCA methodology. Environ. Impact Assess. Rev. 20, 113-123.

[13] Ekvall T and Weidema B. 2004. System boundaries and input data in consequential life cycle inventory analysis. Int $\mathrm{J}$ Life Cycle Assess 9 (3): 161-171.

[14] Weidema B P, Frees N, Nielsen A M. 1999. Marginal production technologies for life cycle inventories. Int. J. Life Cycle Assess. 4, 448-456.

[15] Eriksson O, Finnveden G, Ekvall T, Bjo“ rklund A. 2007. Life Cycle Assessment of fuels for district heating: a comparison of waste incineration, biomass- and natural gas combustion. Energy Policy 35, 1346-1362.

[16] Ekvall T. 2000. A market-based approach to allocation at openloop recycling. Resour. Conserv. Recycling 29 (1-2), 93-111.

[17] Ekvall T and Andrae A. 2006. Attributional and consequential environmental assessment of the shift to lead-free solders. Int. J. LCA 11 (5), 344-353.

[18] Lesage P, Ekvall T, Deschenes L, Samson R. 2007a. Environmental assessment of brownfield rehabilitation using two different life cycle inventory models: Part I: Methodological approach. Int. J. Life Cycle Assess 12, 391-398. 
[19] Lesage P, Ekvall T, Deschenes L, Samson R. 2007b. Environmental assessment of brownfield rehabilitation using two different life cycle inventory models: Part 2: Case study. Int. J. Life Cycle Assess. 12, 497-513.

[20] Kløverpris J, Wenzel H, Nielsen P H. 2008. Life cycle inventory modelling of land use induced by crop consumption. Part 1: Conceptual analysis and methodological proposal. Int. J. LCA 13, 13-21.

[21] Ibenholt K. 2002. Materials flow analysis and economic modelling. In: Ayres, R. U., Ayres, L. W. (Eds.), Handbook of Industrial Ecology. Edward Elgar, Cheltenham, pp. 177184.

[22] Thiesen J, Christensen T S, Kristensen T G, Andersen R D, Brunoe B, Gregersen T K, Thrane M, Weidema B P. 2008. Rebound effects of price differences. Int. J. LCA 13, 104-114.

[23] Spielmann M, de Haan P, Scholz R W. 2008. Environmental rebound effects of high-speed transport technologies: a case study of climate change rebound effects of a future underground maglev train system. J. Cleaner Prod. 16, 13881398.

[24] Weidema B P, Wesnæs M, Hermansen J, Kristensen T, Halberg N, Eder P, Delgado L. 2008. Environmental improvement potentials of meat and dairy products. Institute for Prospective Technological Studies, Sevilla.

[25] Claeson U. 2000. Analyzing Technological Change Using Experience Curves - A Study of the Combined Cycle Gas Turbine Technology. LicEng thesis, Chalmers University of Technology, Gothenburg, Sweden.

[26] Ekvall T, Mattsson N, Münter M. 2006. Consequential modelling of Vistar combustion: a feasibility study. In: Abstracts - 16th Annual Meeting of SETAC - Europe, The Hague, The Netherlands, May 2006, p. 281.

[27] Mattsson N. 1997. Internalizing Technological Development in Energy Systems Models. LicEng thesis, Chalmers University of Technology, Gothenburg, Sweden

[28] Stewart M and Weidema B. 2005. A consistent framework for assessing the impacts from resource use. Int. J. LCA 10, 240 247.

[29] Steen B. 1999. A Systematic Approach to Environmental Priority Strategies in Product Development (EPS). Version 2000 - General System Characteristics/ Models and Data of the Default Method. CPM Report 1999 and CPM Report 1999, Chalmers University of Technology, Gothenburg, Sweden, p. 4 and 5.

[30] Goedkoop M and Spriensma R. 2000. The Eco-indicator 99 A Damage-oriented Method for Life Cycle Impact
Assessment. Methodology Report, second ed., 17- 4-2000. Pre' Consultants, B. V. Amersfoort, The Netherlands.

[31] Rebitzer G, Ekvall T, Frischknecht R, Hunkeler D, Norris G, Rydberg T, Schmidt W P, Suh S, Weidema B P, Pennington D W. 2004. Life cycle assessment - Part 1: Framework, goal \& scope definition, inventory analysis, and applications. Environ. Int. 30, 701-720.

[32] Mattsson N, Unger T, Ekvall T. 2003. Effects of perturbations in a dynamic system - the case of nordic power production. In: Unger, T. (Ed.), Common Energy and Climate Strategies for the Nordic Countries - A Model Analysis. PhD thesis, Chalmers University of Technology, Go"teborg, Sweden.

[33] Yang Y. 2017a. Personal Communiction.

[34] Yang Y. 2017b. Does hybrid LCA with a complete system boundary yield adequate results for product promotion? Int J Life Cycle Assess 22 (3): 456-406.

[35] Weidema B P and Schmidt J H. 2010. Avoiding Allocation in Life Cycle Assessment Revisited. Journal of Industrial Ecology, 14: 192-195. doi: 10.1111/j.1530-9290.2010.00236.x.

[36] Consequential-LCA (2015). Marginal Suppliers. Last updated: 2015-06-18 https://consequential-lca.org/clca/marginalsuppliers/.

[37] Weidema. 2017. Personal communications.

[38] EN 15804: 2012. 2012 Sustainability of construction works Environmental product declaration - Core rules for the product category of construction products.

[39] Google. 2017. https://environment.google/projects/announcement-100/.

[40] Zamagni A, Guinée J, Heijungs R, Masoni P, Raggi A. 2012. Lights and shadows in consequential LCA Int J Life Cycle Assess 17 (3): 904-918.

\section{Biography}

Nigel Howard is an independent LCA researcher and consultant specialising in buildings and infrastructure. He is a former Director of the UK Centre for Sustainable Construction, a former Vice President and CTO of the US Green Building Council, a former President of the Australian Life Cycle Assessment Society and the founding Chairman and former Managing Director of the Edge Environment Consultancy. He has developed the ENVESTTM series of LCA/LCC based building design tools. 